\title{
Microwave digestion of zircon with ammonium acid fluoride: derivation of kinetic parameters from non-isothermal reaction data
}

\author{
T.N. Nhlabathi ${ }^{\mathrm{a}}$, J.T. Nel ${ }^{\mathrm{a}}$, G.J. Puts ${ }^{\mathrm{b}}$, and P.L. Crouse ${ }^{* \mathrm{~b}}$. \\ ${ }^{a}$ The South African Nuclear Energy Corporation Ltd. (Necsa), P.O Box 582, Pretoria, 0001, South Africa, \\ ${ }^{b}$ Department of Chemical Engineering, University of Pretoria, Pretoria, 0002, South Africa. \\ *Corresponding Author.e-mail:philip.crouse@up.ac.za \\ Tel: (+27)124202856 \\ Fax (+27)12420 5048
}

\begin{abstract}
Zircon is notoriously inert. Aggressive processing methods such as alkaline fusion are conventionally used to extract zirconium values from the mineral. In this study results are presented with respect to microwave digestion of zircon using ammonium acid fluoride $\left(\mathrm{NH}_{4} \mathrm{~F} \cdot 1.5 \mathrm{HF}\right)$. Two distinct experimental methods were used. In the first method the reaction was followed in the temperature range 100 to $200{ }^{\circ} \mathrm{C}$, for a full reaction period of 60 minutes at each temperature. The second method comprised successive digestion periods interrupted by washing and re-introduction of fresh acid fluoride at a series of reaction temperatures varying between 120 and $240{ }^{\circ} \mathrm{C}$. Complete digestion was achieved with the latter technique. The kinetics is shown to be controlled by product-layer diffusion. The two data sets were combined to derive consistent temperature-dependent kinetic parameters. A facile numerical technique for extracting these parameters from the experimental data is used.
\end{abstract}

Key words: zircon, microwave digestion, ammonium acid fluoride, kinetics 


\section{Introduction}

Zircon is chemically extremely inert [Wilks et al., 1974]. The mineral is usually processed using relatively aggressive conditions, such as alkaline smelting with $\mathrm{NaOH}$ at $600{ }^{\circ} \mathrm{C}$, or with $\mathrm{Na}_{2} \mathrm{CO}_{3}$ at $1200{ }^{\circ} \mathrm{C}$ [Stevens, 1986]:

$$
\begin{gathered}
\mathrm{ZrSiO}_{4}+4 \mathrm{NaOH} \stackrel{600^{\circ} \mathrm{C}}{\longrightarrow} \mathrm{Na}_{2} \mathrm{ZrO}_{3}+\mathrm{Na}_{2} \mathrm{SiO}_{3}+2 \mathrm{H}_{2} \mathrm{O} \\
\mathrm{ZrSiO}_{4}+2 \mathrm{Na}_{2} \mathrm{CO}_{3} \stackrel{1200^{\circ} \mathrm{C}}{\longrightarrow} \mathrm{Na}_{2} \mathrm{ZrO}_{3}+\mathrm{Na}_{2} \mathrm{SiO}_{3}+2 \mathrm{CO}_{2}
\end{gathered}
$$

Separation of the sodium zirconate from the sodium silicate is achieved by dissolution in water, filtration, and precipitation. Alternatively zirconium tetrachloride is produced by carbo-chlorination of zircon at $>800{ }^{\circ} \mathrm{C}$ according [Bidaye et al., 1999]:

$$
\mathrm{ZrSiO}_{4}+4 \mathrm{Cl}_{2}+2 \mathrm{C} \stackrel{>800^{\circ} \mathrm{C}}{\longrightarrow} \mathrm{ZrCl}_{4}+\mathrm{SiCl}_{4}+2 \mathrm{CO}_{2}
$$

Depending on the temperature, $\mathrm{CO}$ can also form in reaction (3). The $\mathrm{ZrCl}_{4}$ and $\mathrm{SiCl}_{4}$ are separated by distillation. $\mathrm{ZrCl}_{4}$ serves as a starting material for the manufacture of the metal and its alloys, as well as several zirconium chemicals.

Zircon can also be made chemically reactive by dissociation in a plasma tail-flame at $>1700{ }^{\circ} \mathrm{C}$, producing so-called plasma-dissociated zircon (PDZ, $\mathrm{ZrO}_{2} \cdot \mathrm{SiO}_{2}$ ). This material is essentially microcrystalline zirconia particles embedded in an amorphous silica matrix. The amorphous silica can be selectively removed using a concentrated $\mathrm{NaOH}$ solution, or completely dissolved using aqueous HF [Williamson and Evans, 1979; Wilks et al., 1972; McPherson and Shafer, 1985; Nel, 1999]:

$$
\begin{gathered}
\mathrm{ZrSiO}_{4} \stackrel{>170{ }^{\circ} \mathrm{C}}{\longrightarrow} \mathrm{ZrO}_{2} \cdot \mathrm{SiO}_{2} \\
\mathrm{ZrO}_{2} \cdot \mathrm{SiO}_{2}+\mathrm{NaOH}(\mathrm{aq}) \rightarrow \mathrm{ZrO}_{2}+\mathrm{Na}_{2} \mathrm{SiO}_{3}+\mathrm{H}_{2} \mathrm{O} \\
\mathrm{ZrO}_{2} \cdot \mathrm{SiO}_{2}+12 \mathrm{HF}(\mathrm{aq}) \rightarrow \mathrm{H}_{2} \mathrm{ZrF}_{6}+\mathrm{H}_{2} \mathrm{SiF}_{6}+4 \mathrm{H}_{2} \mathrm{O}
\end{gathered}
$$


The $\mathrm{H}_{2} \mathrm{ZrF}_{6}$ and $\mathrm{H}_{2} \mathrm{SiF}_{6}$ are separated by evaporative crystallization. The crystallization also serves as a purification step for the $\mathrm{H}_{2} \mathrm{ZrF}_{6}$. Pure $\mathrm{ZrO}_{2}$ can be produced from $\mathrm{H}_{2} \mathrm{ZrF}_{6}$ by steam pyrolysis:

$$
\mathrm{H}_{2} \mathrm{ZrF}_{6}+2 \mathrm{H}_{2} \mathrm{O} \stackrel{600-800{ }^{\circ} \mathrm{C}}{\longrightarrow} \mathrm{ZrO}_{2}+6 \mathrm{HF}
$$

PDZ can alternatively be subjected to dry fluorination using anhydrous HF [Nel, 1997]:

$$
\mathrm{ZrO}_{2} \cdot \mathrm{SiO}_{2}+4 \mathrm{HF}(\mathrm{g}) \rightarrow \mathrm{ZrO}_{2}(\mathrm{~s})+\mathrm{SiF}_{4}+2 \mathrm{H}_{2} \mathrm{O}
$$

We here extend work reported recently [Nel et al., 2011] in which results pertaining to the microwave digestion of zircon with ammonium acid fluoride (AAF) were presented. It was shown that complete dissolution could be achieved if the unreacted zircon is intermittently removed from the digestion vessel, washed with water, and re-introduced into the system with fresh AAF. The rate limiting step was tentatively identified as product-layer diffusion, and an effective diffusion constant derived on the assumption of a linear contribution to the reaction time by the heating and cooling steps. Here we introduce a more correct method for extraction of the kinetic data from what is essentially a non-isothermal system, and introduce new data pertaining to the case where the product is not subjected to repeated washing cycles.

\section{Experimental}

\subsection{Chemicals and apparatus}

Prime grade zircon $\left(\mathrm{d}_{50}\right.$ particle size $\left.125 \mu \mathrm{m}\right)$ obtained from Namakwa Sands was used. Ammonium acid fluoride (AAF, $\mathrm{NH}_{4} \mathrm{~F} \cdot 1.5 \mathrm{HF}$ ) was obtained from Pelchem Ltd. $\mathrm{HF}$ (40\%) and $\mathrm{H}_{3} \mathrm{BO}_{3}$ were Merck analytical grade. All chemicals had a purity of $>99 \%$. A CEM Mars 5 programmable microwave unit was used for digestion experiments. The system is capable of delivering a maximum power of $1600 \mathrm{~W}$ at a frequency of $2450 \mathrm{MHz}$. The sample carousel allows for up to twelve digestion vessels to be mounted simultaneously, one of which is a control vessel for monitoring of pressure and 
temperature. These data are used for feedback control of the reaction conditions. The carousel rotates slowly through $360{ }^{\circ} \mathrm{C}$ during processing. CEM XP-1500 PFA lined digestion vessels $(100 \mathrm{ml})$ and caps were used in these experiments. The maximum recommended working pressure and temperature of the vessels are $5.5 \mathrm{MPa}$ and $240{ }^{\circ} \mathrm{C}$ respectively. In all cases temperature was controlled, and reactor pressure monitored. The residue was analyzed by FT-Raman spectrometry (Bruker Ram II) and XRD (Bruker A-D8 Advance), as reported by Nel et al. [2011].

\subsection{Experimental procedures}

It is assumed that the reaction between zircon and $\mathrm{NH}_{4} \mathrm{~F} \cdot 1.5 \mathrm{HF}$ proceeds according to:

$$
3 \mathrm{ZrSiO}_{4}+16 \mathrm{NH}_{4} \mathrm{~F} \cdot 1.5 \mathrm{HF} \rightarrow 3\left(\mathrm{NH}_{4}\right)_{3} \mathrm{ZrF}_{7}+3\left(\mathrm{NH}_{4}\right)_{2} \mathrm{SiF}_{6}+12 \mathrm{H}_{2} \mathrm{O}+\mathrm{NH}_{4} \mathrm{~F}
$$

The AAF and ammonium fluoride, as well as the two ammonium fluorometallates, $\left(\mathrm{NH}_{4}\right)_{3} \mathrm{ZrF}_{7}$ and $\left(\mathrm{NH}_{4}\right)_{2} \mathrm{SiF}_{6}$, are totally soluble in water [Hala, 1989; Frayret et al., 2006]. The fractional conversion, $\alpha$, is thus readily obtained by washing, filtering, and drying the zircon residue after time $t$. The fractional conversion $\alpha$ is defined as the ratio of the residual mass $m_{\text {Residue }}$ and the initial mass $m_{0}$.

A starting mass of $0.5 \mathrm{~g}$ zircon was used for each set of experiments. This was mixed with $5 \mathrm{~g}$ of $\mathrm{NH}_{4} \mathrm{~F} \cdot 1.5 \mathrm{HF}$ in the microwave vessel. Assuming that the reaction proceeds according to Equation (9), this represents a roughly 5:1 excess based on AAF. The vessel was capped and placed in the microwave system for the desired time at a selected temperature setting. After completion, the vessel was cooled to room temperature, uncapped, and the reaction stopped by addition of $50 \mathrm{ml}$ of a $3 \%$ boric acid $\left(\mathrm{H}_{3} \mathrm{BO}_{3}\right)$

solution to neutralise the remaining free and bound HF. The reaction proceeds according to Equations (10) and (11), with the formation of water-soluble $\mathrm{HBF}_{4}$ and $\mathrm{NH}_{4} \mathrm{BF}_{4}$ :

$$
\begin{gathered}
4 \mathrm{HF}+\mathrm{H}_{3} \mathrm{BO}_{3} \rightarrow \mathrm{HBF}_{4}+3 \mathrm{H}_{2} \mathrm{O} \\
2 \mathrm{NH}_{4} \mathrm{~F} \cdot 1.5 \mathrm{HF}+\mathrm{H}_{3} \mathrm{BO}_{3} \rightarrow \mathrm{NH}_{4} \mathrm{~F}+\mathrm{NH}_{4} \mathrm{BF}_{4}+3 \mathrm{H}_{2} \mathrm{O}
\end{gathered}
$$


The reaction mixture was centrifuged and the supernatant liquid decanted. The solid residue was washed with water and propanol, dried at $80^{\circ} \mathrm{C}$ for 3 hours and weighed.

Two distinct experimental procedures were employed. In the first case (Procedure 1), samples were digested for full reaction times (excluding heating and cooling times) of 10 , 20, 30, and 60 minutes for the reaction temperatures $100,120,140,160,180$, and $200{ }^{\circ} \mathrm{C}$. Thus for each reaction temperature four samples were used, and for each of these data points an initial and final value of $\alpha$ was obtained. In the second case (Procedure 2) one sample was used for each of reaction temperatures 120,140,160,180, 200, 220, and $240{ }^{\circ} \mathrm{C}$. The reaction temperatures $100,120,140,160,180,200,220$, and $240{ }^{\circ} \mathrm{C}$ correspond to reactor pressure values of $15,20,27,30,32,37,39$, and 45 bar respectively. For each temperature the sample was removed after ten minutes and the residual mass fraction determined after washing and drying as described above. The same sample was then re-introduced into the digestion vessel, and treated again. These cycles were repeated with a ten minute extension of reaction time up to a maximum of 60 minutes (total digestion time per series $260 \mathrm{~min}$ ).

\section{Results and discussion}

The experimental results are given in Table 1 and Table 2 for Procedures 1 and 2 respectively. In both cases an increase in temperature clearly increases the rate of conversion of zircon. For Procedure 1 where no washing of the residue was performed, a minimum $\alpha$ value of 0.69 was obtained. This corresponds to $30 \%$ conversion only. For Procedure 2 about 30\% ( $\alpha=0.70$ ) of the zircon was converted at $120{ }^{\circ} \mathrm{C}$ after $285 \mathrm{~min}$, while $>99 \%(\alpha=0.007)$ conversion was achieved at $240{ }^{\circ} \mathrm{C}$, the highest temperature investigated.

A number of kinetic models are possible for fluid-solid reactions [Levenspiel, 1999]. Based on our previous analysis and, more importantly, the fact that washing of the product layer is required for full conversion, we only consider the ash-layer diffusion control model here. For the general solid-fluid reaction 


$$
\text { A (fluid) }+ \text { bB (solid) } \rightarrow \text { products }
$$

the rate expression is given by [e.g. Levenspiel, 1999]

$$
3 \alpha^{2 / 3}-2 \alpha=1-\frac{t}{\tau}
$$

with

$$
\tau=\frac{\rho_{s} r_{0}^{2}}{6 b M_{s} D_{e} c}
$$

Here $\tau$ is the full time for complete conversion, $M_{s}$ and $\rho_{s}$ are the molecular weight (183.3 g.mol ${ }^{-1}$ ) and density $\left(4.65\right.$ g. $\left.\mathrm{cm}^{-3}\right)$ respectively of the solid zircon, $r_{0}$ is the initial radius of the zircon particles (taken as $63 \mu \mathrm{m}$ on average), $t$ is the reaction time, $b$ and $c$ are the solid stoichiometric coefficient and the concentration of the active species (taken to be $\mathrm{HF}$ ) in the melt, and $D_{e}$ is the effective diffusion coefficient of the active species in the fluid through the product layer. The model asumes sphericity. In reality our particles deviated from this somewhat. In order to obtain an experimental value for $D_{e}$ the left hand side of Equation (13) is plotted against time, $\tau$ is obtained from the slope, and $D_{e}$ is calculated from $\tau$. Linearity indicates model acceptability.

Equation (13) applies to isothermal conditions. Because the reactants have to be heated and cooled while in the digestion vessel, for periods of 10 and 15 minutes respectively in our case, an attempt should be made to compensate for these two periods. For constant heating rate this can be done in the following manner. The rate law is first differentiated, yielding

$$
2 \alpha^{-1 / 3} \frac{d \alpha}{d t}-2 \frac{d \alpha}{d t}=\frac{1}{\tau}
$$

Application of the chain rule results in 


$$
2 \alpha^{-1 / 3} \frac{d \alpha}{d T} \frac{d T}{d t}-2 \frac{d \alpha}{d T} \frac{d T}{d t}=\frac{1}{\tau}
$$

The assumption of a constant heating rate, $d T / d t=\beta$, and separation of variables yield

$$
2 \alpha^{-1 / 3} d \alpha-2 d \alpha=\frac{d T}{\beta \tau}
$$

Integration based on the assumption that the effective diffusion constant displays Arrhenius behaviour, returns

$$
3 \alpha^{2 / 3}-2 \alpha-1=-\frac{6 b c M_{s}}{\beta \rho_{s} r_{0}^{2}} \int_{T_{0}}^{T} D_{0} e^{-\frac{E_{a}}{R T}} d T
$$

The integral on the right hand side does not have an easy analytical solution, but can quite readily be integrated numerically. An objective function, $O F$, which combines Equations (13) and (18) can now be constructed for the full set of data points of Procedures 1 and 2, and minimized with respect to the two constants $D_{0}$ and $E_{a}$ to obtain values for these two parameters. The objective function is

$$
\begin{aligned}
& O F=\sum_{i=1}^{n} \mid 3 \alpha_{i}^{2 / 3}-2 \alpha_{i}-1 \\
& +\frac{6 b c M_{s} D_{0}}{\rho_{s} r_{0, i}^{2}}\left[\frac{1}{\beta_{\text {heating }}} \int_{T_{0}}^{T_{\text {reaction }}} e^{-\frac{E_{a}}{R T}} d T+\frac{1}{\beta_{\text {cooling }}} \int_{T_{\text {reaction }}}^{T_{0}} e^{-\frac{E_{a}}{R T}} d T+e^{-\frac{E_{a}}{R T_{\text {reacton }}}} t_{\text {reaction }}\right] \mid
\end{aligned}
$$

Several algorithms are possible to minimize (19), [e.g. Puxty et al., 2006]. A simple grid search was implemented for the purpose in our case. In practice the inverse of the objective function (19) was maximized, it yielding a much more clearly defined optimum. For Procedure 2, where the particles were washed after each successive digestion step, the processing history of the material is effectively removed with each wash. The use of the cumulative processing time is thus not valid and $r_{0}$ in Equation (19) has to be replaced by the initial particle radius for each step. For the diffusion constant 
the values $D_{0}=9.4 \times 10^{-13} \mathrm{~m}^{2} \cdot \mathrm{s}^{-1}$ and $\mathrm{E}_{\mathrm{a}}=46.1 \mathrm{~kJ} \cdot \mathrm{mol}^{-1}$ were obtained. The magnitude of the diffusion constant for this case lies between $10^{-15}$ and $10^{-17} \mathrm{~m}^{2} . \mathrm{s}^{-1}$, depending on temperature. This is several orders of magnitude lower than for molecular diffusion through liquids, and typical for molecular diffusion through solids [Bird et al., 1960; Geankoplis, 1978].

Experimental data points for both procedures, along with $\alpha$ values calculated using the derived Arrhenius parameters, are graphically displayed in Figure 1 and Figure 2. The numerical behaviour of the objective function is illustrated in Figure 3, and the behaviour of its inverse in Figure 4.

This is strong experimental evidence for the interpretation that an adhesive layer of ammonium fluoro-silicate-zirconate forms around each particle, inhibiting access by the diffusing $\mathrm{HF} / \mathrm{HF}_{2}^{-}$, and controlling the process kinetics.

\section{Conclusions}

For microwave digestion of zircon in ammonium acid fluoride as demonstrated here, the process is controlled by the diffusion rate of the active fluid species through the ammonium fluorometallate product layer. Zircon can be converted practically quantitatively to water soluble products by repeated removal of the product layer by washing. The order of magnitude value of the diffusion constant calculated from this

work corresponds to that for diffusion in solids. The results suggest that a high-pressure vessel which allows vigorous agitation might improve the yield without washing steps.

\section{Acknowledgements}

The authors wish to thank: The South African Nuclear Energy Corporation Ltd (Necsa) for making facilities available and allowing these results to be published; The Advanced Metals Initiative of the Department of Science and Technology of South Africa for 
financial support; and The National Research Council for supporting the activities at the University of Pretoria. 


\section{References}

Bidaye, A.C., Venkatachalam, S., Gupta, C.K., 1999. Studies on the chlorination of zircon: Part I. Static bed investigations. Metall. Mater. Trans. B, 30B, 205-213.

Bird, R.B., Stewart, W.E., Lightfoot, E.N., 1960. Transport Phenomena, $2^{\text {nd }}$ Edition. John Wiley and Sons, New York

Frayret, J., Castetbon, A., Trouve, G., Potin-Gautier, M., 2006. Solubility of $\left(\mathrm{NH}_{4}\right)_{2} \mathrm{SiF}_{6}$, $\mathrm{K}_{2} \mathrm{SiF}_{6}$ and $\mathrm{Na}_{2} \mathrm{SiF}_{6}$ in acidic solutions. Chemical Physics Letters, 427(4-6), 356364.

Geankoplis, C.J., 1978. Transport Processes and Unit Operations. Allyn and Bacon, Inc., Boston.

Hala, J., 1989. Halides, oxyhalides and salts of halogen complexes of titanium, zirconium, hafnium, vanadium, niobium and tantalum, IUPAC Solubility Data Series, Vol 40, p 58.

Levenspiel, O., 1999. Chemical Reaction Engineering, $3^{\text {rd }}$ Edition. John Wiley and Sons, New York.

McPherson, R. and Shafer, R.B.V., 1985. The re-association of plasma dissociated zircon. J. Mater. Sci., 20, 2597-2602.

Nel, J., 1997. Process for reacting dissociated zircon with gaseous hydrogen fluoride. US Patent 5,688,477.

Nel, J.T., 1999. Process for reacting a zirconia-based material. US Patent 5,958,355.

Nel, J.T., du Plessis, W., Nhlabathi, T.N., Pretorius, C.J., Jansen, A.A., Crouse, P.L., 2011. Reaction kinetics of the microwave digestion of zircon with ammonium fluoride. Journal of Fluorine Chemistry 132, 258-262.

Puxty, G., Maeder, M., Hungerbühler, K., 2006. Tutorial on fitting of kinetic models to multivariate spectroscopic measurements with non-linear least-squares regression. Chemometrics and Intelligent Laboratory Systems, 81, 149-164.

Stevens, R., 1986. Zirconia and Zirconia Ceramics. Magnesium Elektron Ltd., Twickenham, England.

Wilks, P.H., Ravinder, P., Grant, C.L., Pelton, P.A., Downer, R.J., Talbot, M.L., 1972. Plasma process for zirconium dioxide. Chem. Eng. Prog., 68(4), 82-83. 
Wilks, P.H., Ravinder, P., Grant, C.L., Pelton, P.A., Downer, R.J., Talbot, M.L., 1974. Commercial production of submicron $\mathrm{ZrO}_{2}$ via plasma. Chem. Eng. World, 9(3) 59-65.

Williamson, J.P.H. and Evans, A.M., 1979. Investigations into the characteristics and some potential industrial applications of plasma dissociated zircon. Trans. J. Br. Ceram. Soc., 74(4), 68-77. 


\section{LIST OF TABLES}

Table 1: Fractional conversion data for Procedure 1.

Table 2: Fractional conversion data for Procedure 2, i.e. with intermittent washing and addition of fresh $\mathrm{NH}_{4} \mathrm{~F} \cdot 1.5 \mathrm{HF}$.

\section{LIST OF FIGURES}

Figure 1: Experimental and theoretical data for Procedure 1.

Figure 2: The effect of temperature and repeated addition of $\mathrm{NH}_{4} \mathrm{~F} \cdot 1.5 \mathrm{HF}$ on the conversion of zircon.

Figure 3: Convergence behaviour of the objective function.

Figure 4: Convergence behaviour of the inverse of the objective function. 


\section{TABLES}

Table 1: Fractional conversion data for Procedure 1.

\begin{tabular}{|c|c|c|c|c|c|c|}
\hline Time (min) & $\begin{array}{c}100^{\circ} \mathrm{C} \\
\alpha\end{array}$ & $\begin{array}{c}120^{\circ} \mathrm{C} \\
\alpha\end{array}$ & $\begin{array}{c}140^{\circ} \mathrm{C} \\
\alpha\end{array}$ & $\begin{array}{c}160^{\circ} \mathrm{C} \\
\alpha\end{array}$ & $\begin{array}{c}180^{\circ} \mathrm{C} \\
\alpha\end{array}$ & $\begin{array}{r}200^{\circ} \mathrm{C} \\
\alpha\end{array}$ \\
\hline 0 & 1 & 1 & 1 & 1 & 1 & 1 \\
\hline 10 & 0.97 & 0.92 & 0.91 & 0.83 & 0.84 & 0.81 \\
\hline 20 & 0.97 & 0.93 & 0.88 & 0.84 & 0.81 & 0.75 \\
\hline 30 & 0.94 & 0.93 & 0.87 & 0.81 & 0.76 & 0.72 \\
\hline 60 & 0.95 & 0.89 & 0.82 & 0.77 & 0.69 & 0.69 \\
\hline
\end{tabular}


Table 2: Fractional conversion data for Procedure 2, i.e. with intermittent washing and addition of fresh $\mathrm{NH}_{4} \mathrm{~F} \cdot 1.5 \mathrm{HF}$.

\begin{tabular}{cccccccc}
\hline $\begin{array}{c}\text { Cumulative } \\
\text { digestion time } \\
\text { (min) }\end{array}$ & $\boldsymbol{\alpha}$ & $\boldsymbol{\alpha}$ & $\boldsymbol{\alpha}$ & $\boldsymbol{\alpha}$ & $\boldsymbol{\alpha}$ & $\boldsymbol{\alpha}$ & $\boldsymbol{\alpha}$ \\
\hline 0 & 1 & 1 & 1 & 1 & 1 & 1 & 1 \\
22.5 & 0.933 & 0.927 & 0.873 & 0.843 & 0.743 & 0.637 & 0.667 \\
55.0 & 0.847 & 0.847 & 0.767 & 0.653 & 0.553 & 0.533 & 0.340 \\
97.5 & 0.820 & 0.787 & 0.690 & 0.553 & 0.380 & 0.360 & 0.187 \\
150.0 & 0.773 & 0.750 & 0.583 & 0.367 & 0.307 & 0.290 & 0.073 \\
212.5 & 0.733 & 0.703 & 0.477 & 0.253 & 0.167 & 0.163 & 0.047 \\
285.0 & 0.700 & 0.640 & 0.403 & 0.130 & 0.120 & 0.093 & 0.007 \\
\hline
\end{tabular}




\section{FIGURES}

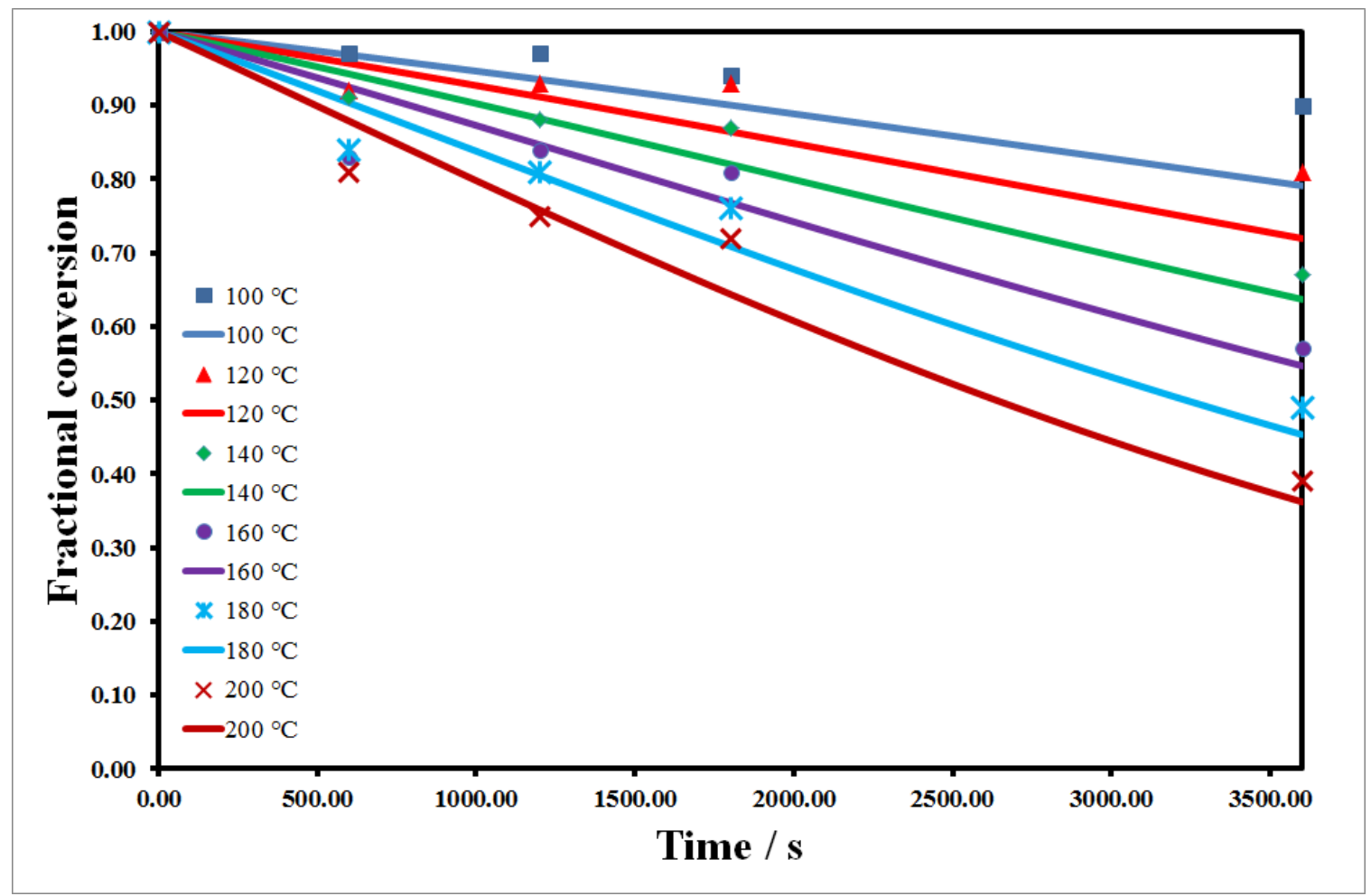

Figure 1: Experimental and theoretical data for Procedure 1. 


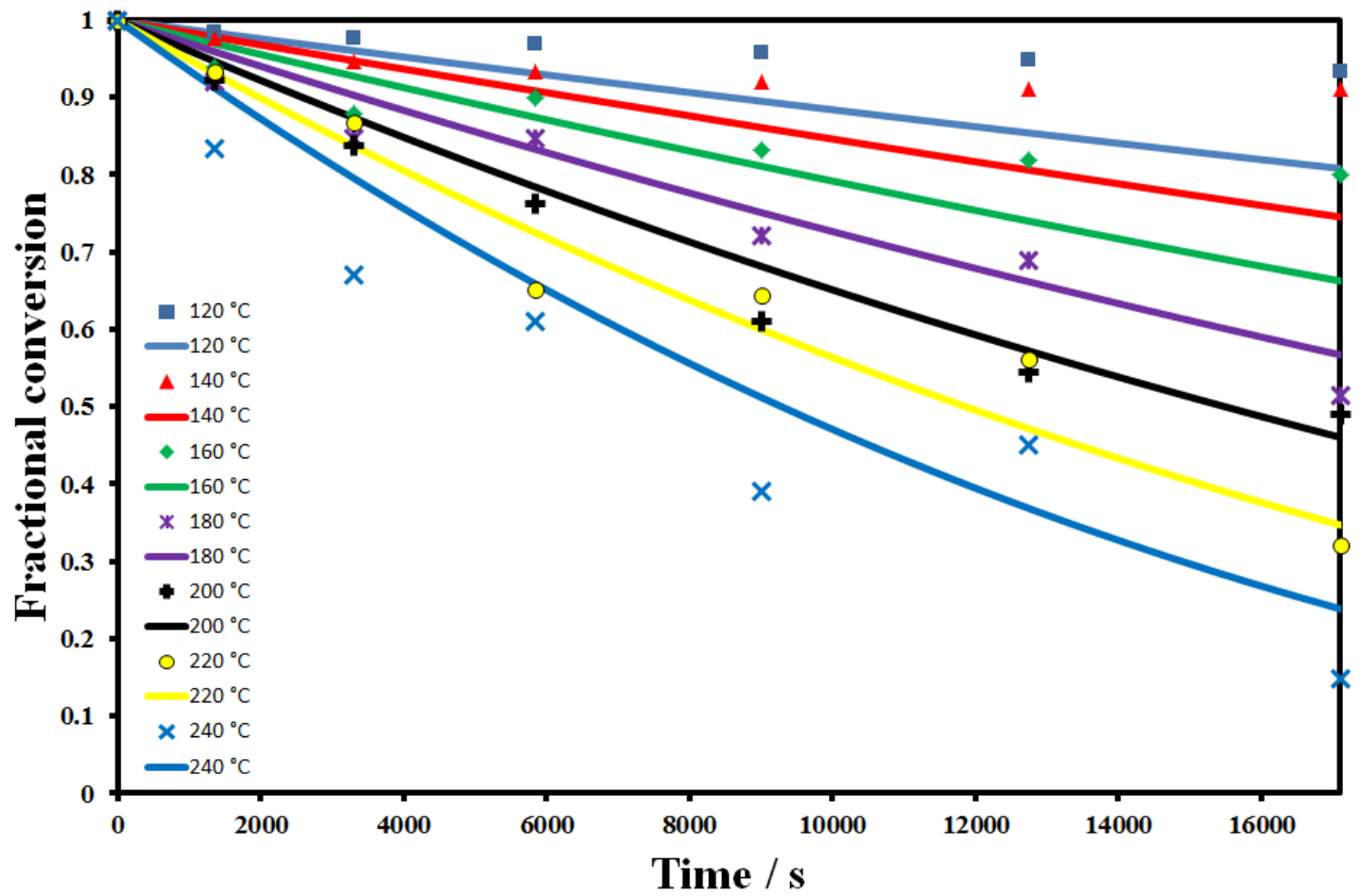

Figure 2: The effect of temperature and repeated addition of $\mathrm{NH}_{4} \mathrm{~F} \cdot 1.5 \mathrm{HF}$ on the conversion of zircon. 


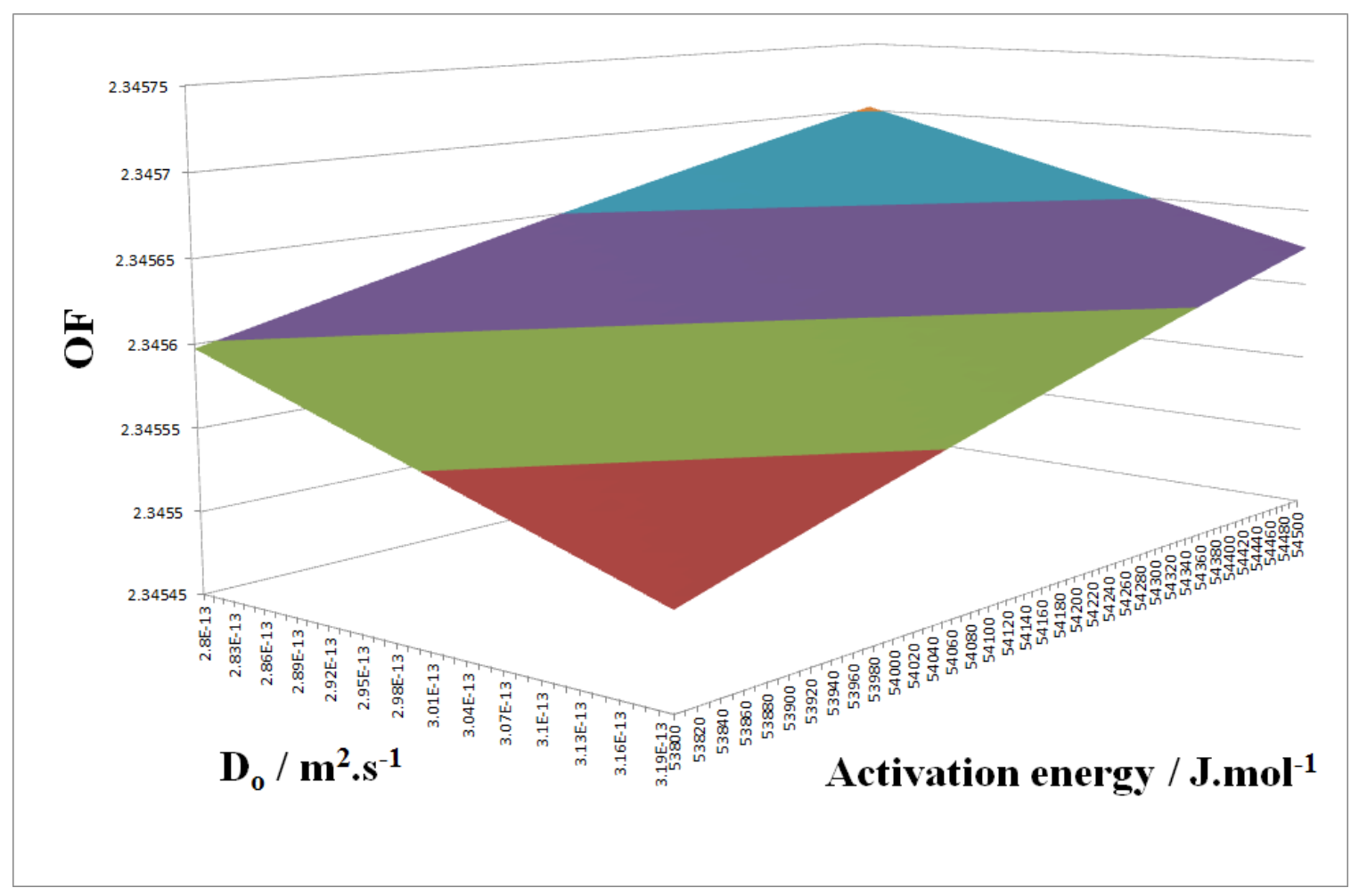

Figure 3: Convergence behaviour of the objective function. 


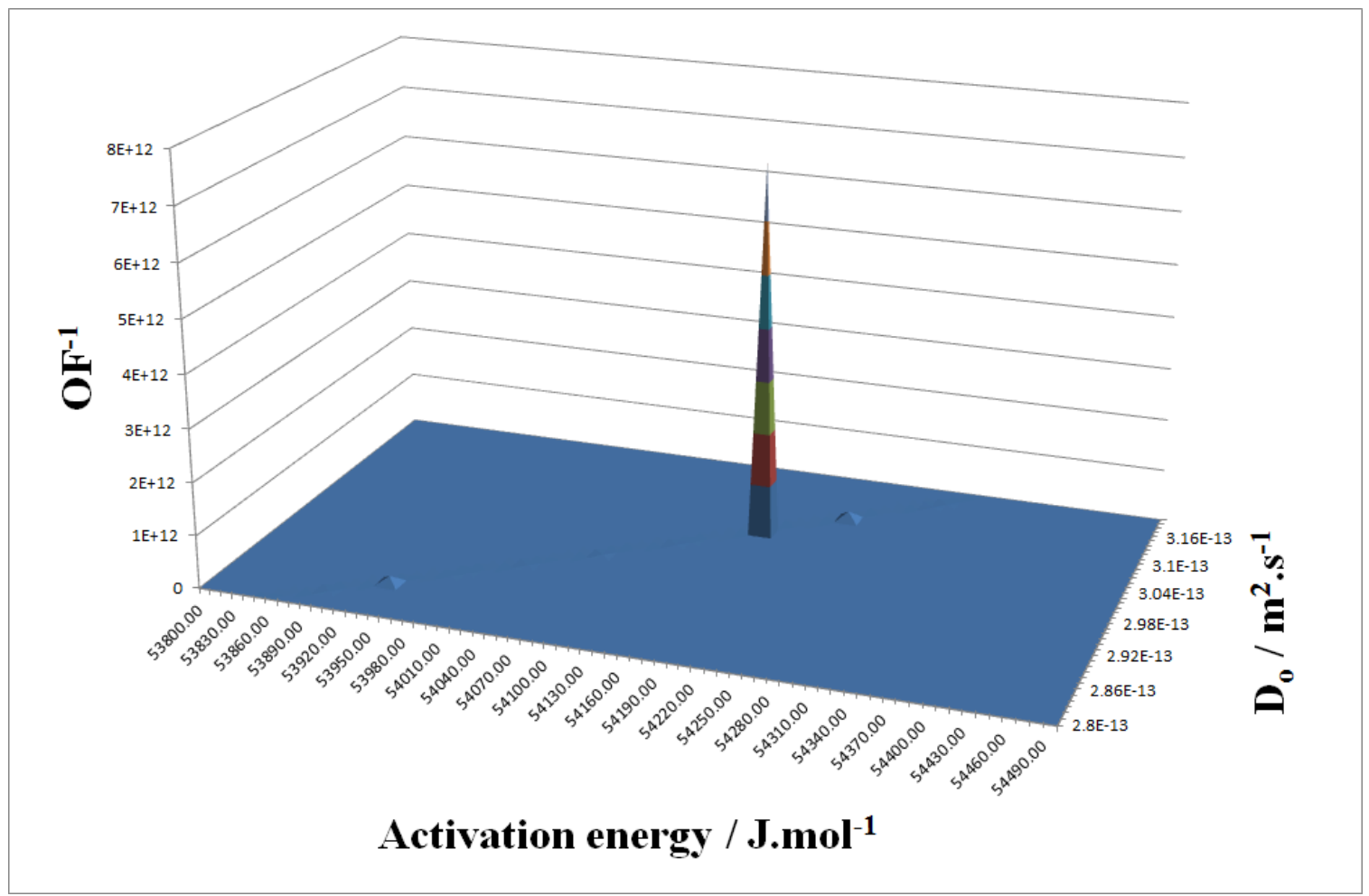

Figure 4: Convergence behaviour of the inverse of the objective function. 